\title{
Germinación de semillas y clave para la identificación de plántulas de seis especies arbóreas nativas de humedales del sureste de México
}

\author{
Luis Felipe Zamora-Cornelio ${ }^{1}$, Susana Ochoa-Gaona ${ }^{1 *}$, Georgina Vargas Simón ${ }^{2}$, Jorge \\ Castellanos Albores ${ }^{3}$ \& Bernardus H.J. de Jong ${ }^{1}$ \\ 1. El Colegio de la Frontera Sur. Sistemas Silvícolas y Agroforestales. Carretera a Reforma km 15.5. R/a. El Guineo \\ 2a. Secc. Centro. Villahermosa, Tabasco. México. Tel. (993) 613-6110; zamlf@yahoo.com.mx, sochoa@ecosur.mx, \\ bjong@ecosur.mx \\ 2. Universidad Juárez Autónoma de Tabasco. km 0.5 carretera Villahermosa - Cárdenas. Villahermosa. Tabasco, México. \\ C.P. 86000; georgina.vargas@dacbiol.ujat.mx \\ 3. El Colegio de la Frontera Sur. Sistemas Silvícolas y Agroforestales. Carretera Panamericana y Periférico Sur S/n. \\ Barrio María Auxiliadora. San Cristóbal de las Casas. Chiapas; jcastell@ecosur.mx \\ * Correspondencia
}

Recibido 21-V-2009. Corregido 09-X-2009. Aceptado 03-XI-2009.

\begin{abstract}
Seed germination and key to seedling identification for six native tree species of wetlands from Southeast Mexico. Wetland tree species are of importance for economic and restoration purposes. We describe the germination process and seedling morphology of six arboreal native species typical of Southeastern Mexico: Annona glabra, Ceiba pentandra, Pachira aquatica, Haematoxylum campechianum, Coccoloba barbadensis and Crataeva tapia. A total of 300 seeds per species were planted in a mixture of sand, cocoa plant husk and black soil (1: 1: 1), and maintained in a tree nursery with $30 \%$ artificial shade, from February to November of 2007. We carried out the morphological characterization, and elaborated a key to seedlings based on: 1) germination type 2) seedling axis and 3) leaf elements. P. aquatica has cryptocotylar hypogeal germination, the others have phanerocotylar epigeal germination. Germination rates were high (>86\%), except for C. barbadensis (69\%). Rev. Biol. Trop. 58 (2): 717-732. Epub 2010 June 02.
\end{abstract}

Key words: germination, native trees, riverine vegetation, seedling morphology, wetlands.

Los humedales tropicales son regiones de notable biodiversidad. La convención RAMSAR (Anónimo 1999) los ha definido como extensiones de marismas, pantanos, turberas o superficies cubiertas de agua, sean éstos naturales o artificiales, permanentes o temporales, con agua estancada o corriente, dulce, salobre o salada, incluidas las extensiones de agua marina cuya profundidad en marea baja no exceda los seis metros. En el mundo existen 557 millones de hectáreas de humedales y se estima que México posee el $0.6 \%$ de éstas, es decir, aproximadamente 3318 500ha (Olmsted 1993). El estado de Tabasco contiene la mayor superficie de humedales del país con 681248 ha (Barba et al. 2006), siendo la Reserva de la Biosfera Pantanos de Centla un sitio de importancia prioritaria para la conservación, ya que posee el museo vivo de plantas acuáticas más importante de Mesoamérica (Lot \& Novelo 1988), y es considerada de amplia importancia ecológica como zona de paso y anidación de aves migratorias (Scott \& Carbonell 1986).

A pesar de su importancia ecológica, los humedales se encuentran en peligro, siendo las principales amenazas a estos ecosistemas: el crecimiento poblacional, la deforestación, la sobreexplotación de pesquerías, los cambios 
de uso del suelo, el relleno y desvío de cauces y los incendios, entre los más importantes (Tabilo-Valdivieso 1997, Dalejones et al. 1999, Gibbs 2000). Se calcula que $35 \%$ de los humedales de México, han sufrido algún deterioro por alguno de estos factores, lo cual pone a sus poblaciones y comunidades en un estado de inminente riesgo de desaparición, por lo que realizar acciones para su restauración es una necesidad vigente.

Actualmente, en muchos países del Neotrópico, entre ellos México, ha aumentado el interés por el uso de especies arbóreas nativas para proyectos de reforestación y rescate de zonas degradadas. En general, estos programas incluyen especies que son útiles para el hombre, lo que puede excluir a especies de importancia ecológica, en particular aquellas que prosperan en ecosistemas frágiles como los humedales, tomando en cuenta que dichos ecosistemas son zonas críticas de transición entre la fase acuática y la terrestre.

El estudio sobre el proceso germinativo y la descripción de las plántulas en especies tropicales es escaso y no se le ha dado la debida importancia, siendo que éstas características son esenciales para evaluar el éxito en programas de reforestación y/o regeneración natural de la vegetación (Schmidt 2000, Capó 2001). En este trabajo, se estudian seis especies arbóreas nativas: Annona glabra L., Ceiba pentandra (L.) Gaertn., Pachira aquatica Aubl., Haematoxylum campechianum L., Coccoloba barbadensis Jacq., Crataeva tapia L., las cuales son propias de humedales, particularmente de áreas ribereñas en la Reserva de la Biosfera Pantanos de Centla, Tabasco, México, cuya cobertura ha sido fuertemente impactada por cambios de uso de suelo a consecuencia de la ganadería (Zenteno et al. 2007). Estas especies son de importante valor ecológico para la restauración de humedales, son abundantes, sirven de alimento y refugio para múltiples especies de fauna, algunas son formadoras de suelo, evitan la erosión fluvial y son útiles en la construcción de viviendas y como combustible; y presentan amplia distribución en América Tropical (Pennington \& Sarukhán 2005).

\section{MATERIALES Y MÉTODOS}

Colecta de frutos y semillas: Los frutos y semillas se colectaron de febrero a septiembre de 2007 en áreas de selva baja subperennifolia de $H$. campechianum, vegetación secundaria y vegetación riparia (Guadarrama-Olivera \& Ortiz-Gil 2000, Romero et al. 2000, NoveloRetana 2006) en la Reserva de la Biosfera Pantanos de Centla, Tabasco (17 $57^{\prime} 53^{\prime \prime}-18^{\circ} 39^{\prime} 03^{\prime}$ " $\mathrm{N}$ y $\left.92^{\circ} 06^{\prime} 39^{\prime \prime}-92^{\circ} 47^{\prime} 58^{\prime \prime} \mathrm{O}\right)$. Este material fue llevado al laboratorio de estudios forestales de El Colegio de la Frontera Sur para su procesamiento y obtención del lote de semillas para la germinación. Los frutos y semillas se colectaron en árboles madre maduros, sanos y de buen porte.

Experimento de germinación: Se llevó a cabo de marzo a noviembre de 2007 en las instalaciones de El Colegio de la Frontera Sur, localizado en el kilómetro 15.5 de la ranchería Guíneo $2^{\mathrm{a}}$. Secc. carretera Villahermosa-Reforma, Tabasco. México. El clima en la región es cálido húmedo $A m(f)$ con abundantes lluvias en verano y dos épocas secas. La temperatura media anual varía entre 24 y $28^{\circ} \mathrm{C}$ y la precipitación promedio anual es de $1600 \mathrm{~mm}$ (García 1988). Una semilla se consideró germinada cuando emergieron los cotiledones o plúmula.

Los frutos se secaron a temperatura ambiente bajo sombra parcial durante dos días para eliminar restos de humedad y se extrajeron las semillas. Se sembraron 60 semillas por especie en recipientes de germinación utilizando como sustrato una mezcla de arena, cascarilla de cacao y arcilla (1:1:1), distribuidas aleatoriamente y con cinco repeticiones. Los recipientes se colocaron en un invernadero bajo sombra al $30 \%$. Debido a que A. glabra y C. barbadensis presentan testa dura e impermeable y con base en lo recomendado por Pedraza (1998) y Duran et al. (2000), se aplicó un tratamiento pregerminativo de escarificación mecánica (lijado de testa) a sus semillas, las especies restantes se sembraron directamente sin tratamiento previo. Se realizó el riego diariamente, así como 


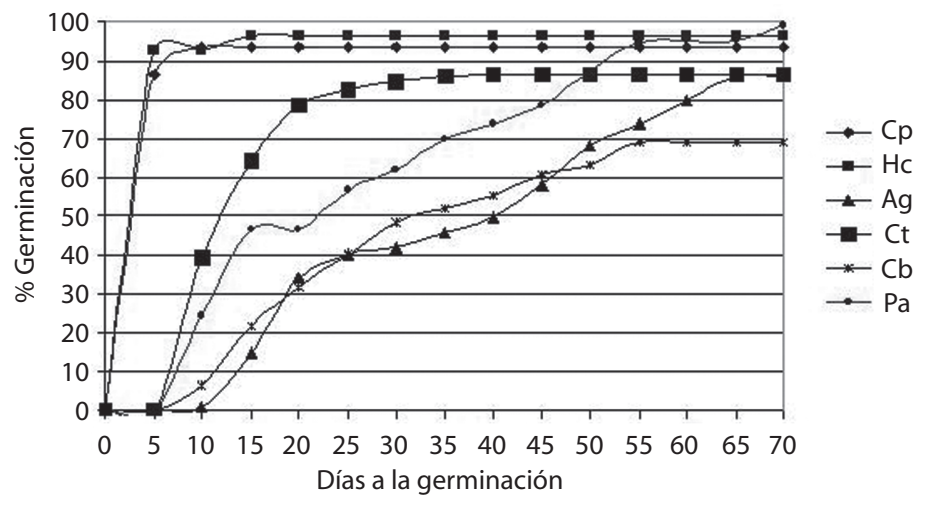

Fig. 1. Germinación acumulada de semillas de seis especies de humedales del Sureste de México. $\mathrm{Cp}=$ Ceiba pentandra, Hc= Haematoxylum campechianum, $\mathrm{Ag}=$ Annona glabra, $\mathrm{Ct}=$ Crataeva tapia, $\mathrm{Cb}=$ Coccoloba barbadensis, $\mathrm{Pa}=$ Pachira aquatica .

Fig.1. Cumulative seed germination curves of six wetland species of Southeast Mexico.

el registro de germinación y temperaturas máximas y mínimas.

De cada especie se recolectaron y procesaron muestras botánicas bajo las técnicas convencionales de herbario de acuerdo a Lot \& Chiang (1986). La identificación se realizó mediante el uso de claves dicotómicas (Standley \& Steyermark 1947, 1976) y por comparación con ejemplares del herbario de la Universidad Juárez Autónoma de Tabasco (UJAT). Los ejemplares se depositaron en el herbario del Colegio de la Frontera Sur (Ecosur).

Clave dicotómica y caracterización morfológica de plántulas: La descripción y caracterización de plántulas se efectúo a partir del material biológico procedente de las pruebas de geminación. Se tomaron de referencia 20 individuos por especie para evaluar las características macroscópicas de las plántulas y de acuerdo a la velocidad de desarrollo de cada una, considerando la edad y aparición de caracteres para su descripción morfológica. Estas características se registraron diariamente para identificar cambios en el proceso de crecimiento y así construir la clave de identificación de plántulas. Se considera la fase de plántula desde que aparece la plúmula hasta el desarrollo de los primeros metafilos. La descripción se realizó con base en las características macroscópicas sugeridas por De Vogel (1980), Ricardi et al. (1987); el tipo de germinación de acuerdo a Garwood (1996) indicadas en el Cuadro 1; se utilizó la terminología botánica indicada por Moreno (1984) y Font Quer (1985). La caracterización y clave dicotómica se basaron en los siguientes datos: 1) tipo de germinación, 2) eje de la plántula y 3) elementos foliares (cotiledones, protofilos y metafilos). Se realizó un registro fotográfico de las diferentes fases de desarrollo.

Análisis estadístico: Se realizó un análisis de varianza (ANOVA) de una vía para determinar las diferencias significativas $(p<0.05)$ entre las especies en: 1) los días en que inició y finalizó la germinación de las semillas, 2) el tiempo de germinación del 50\% de las semillas y 3 ) el total de semillas germinadas al final del experimento. Los datos fueron transformados a escala logarítmica cuando no se cumplieron los supuestos de normalidad y homogeneidad de varianzas (prueba de Levene). Posteriormente, se realizó un análisis post hoc mediante la prueba de Duncan para determinar que especies fueron estadísticamente diferentes en los parámetros antes indicados. Los análisis estadísticos se realizaron mediante el software SPSS 15.0 para Windows (SPSS 2006). 
CUADRO 1

Características macroscópicas consideradas para la descripción morfológica de plántulas

(Basados en De Vogel 1980, Ricardi et al. 1987, Garwood 1996)

TABLE 1

Macroscopic characteristics used for the morphological description of seedlings

(Based on De Vogel 1980, Ricardi et al. 1987, Garwood 1996)

\section{Tipo de germinación \\ Epigea/hipogea. \\ Fanerocotilar/criptocotilar \\ Hipocótilo: recto o curvado.}

2. Eje de la plántula (correspondiente al hipocótilo y epicótilo):

Sección transversal: redonda, cuadrada.

Longitud

Diámetro

Superficie: lenticelada, lisa, etc.

Color

Pubescencia

Presencia de exudaciones o látex.

\section{Elementos foliares}

3.1 Cotiledones:

Tipo: foliáceo, carnoso.

Color:

Tamaño: en mm o cm

Forma

Inserción: sésiles, peciolados.

Nervadura

Duración

\author{
3.2 Protofilos y metafilos: \\ Complejidad: simples o compuestos \\ Número de foliolos \\ Disposición: alternos, opuestos, etc. \\ Duración: persistente, deciduos, etc. \\ Forma: elípticos, ovados, etc. \\ Tamaño (longitud y ancho) \\ Color \\ Consistencia: carnosos, coriáceos, papiráceos. \\ Inserción: sésiles, peciolados, etc. \\ Divisiones: simples, pinnadas, etc. \\ Base: truncada, asimétrica, redonda, etc. \\ Margen: entero, aserrado, ciliado, etc. \\ Ápice: obtuso, acuminado, etc. \\ Superficie: glabra, tomentosa, puberulenta, etc. \\ Nervación: broquidódroma, eucamptódroma, etc. \\ Presencia de estípulas: lineales, redondas, etc. \\ Exudaciones: látex, resina, etc.
}

\section{RESULTADOS}

Germinación: El porcentaje de germinación total entre las especies varió de $69 \%$ a 99\% y el ANOVA mostró diferencias significativas $\left(\mathrm{F}_{5,24}=7.88, \mathrm{p}<0.0001\right)$. Los mayores porcentajes de germinación $(\geq 86 \%)$ son similares entre A. glabra, C. pentandra, C. tapia, $H$. campechianum y $P$. aquatica, en tanto que $C$. barbadensis presentó la menor germinación a pesar de haber sido sometida a escarificación mecánica (69\%, Cuadro 2). Se encontraron diferencias significativas en los días de inicio de la germinación $\left(\mathrm{F}_{5,24}=70.8, \mathrm{p}<0.0000\right)$. $H$. campechianum y $C$. pentandra aunque inician la germinación entre los primeros 2 y 3 días muestran diferencias estadísticas, en tanto que el resto de las especies son similares (6-8 días). Los días de la geminación de la última semilla varió estadísticamente $\left(\mathrm{F}_{5,24}=846.1\right.$, $\mathrm{p}<0.00000$ ), siendo similares los de A. glabra y $P$. aquatica, mientras que las otras especies mostraron diferencias estadísticas entre sí. En cuanto al tiempo en que se alcanzó el $50 \%$ de germinación de semillas también mostró diferencias $\left(\mathrm{F}_{5,24}=555.8, \mathrm{p}<0.00000\right)$. H. campechianum y $C$. pentandra, muestran tiempos similares (4 y 5 días), siendo las más rápidas en alcanzar este promedio y con mayor uniformidad en la germinación. En las especies restantes sus valores variaron entre los 13 a 40 días siendo diferentes estadísticamente entre si (Cuadro 2, Fig. 1).

\section{Descripción y morfología de plántulas:} Se encontró que cinco de las especies presentan germinación fanerocotilar epigea con emergencia del hipocótilo curvada, mientras que en $P$. aquatica fue criptocotilar hipogea con emergencia recta. Los cotiledones de C. tapia y $P$. aquatica son carnosos y en el resto son 
CUADRO 2

Parámetros evaluados en la germinación de semillas de seis especies arbóreas nativas

de humedales del sureste de México

TABLE 2

Germination parameters evaluated in seed germination for six arboreal wetland species, Southeast México

$\begin{array}{lcccccc} & \text { Crataeva } & \text { Pachira } & \text { Haematoxylum } & \text { Ceiba } & \text { Annona } & \text { Coccoloba } \\ \text { Parámetro* } & \text { tapia } & \text { aquatica } & \text { campechianum } & \text { pentandra } & \text { glabra } & \text { barbadensis } \\ \text { Inicio de germinación (días) } & 6^{\mathrm{cd}} & 7^{\mathrm{d}} & 2^{\mathrm{a}} & 3^{\mathrm{b}} & 8^{\mathrm{d}} & 6^{\mathrm{c}} \\ \begin{array}{l}\text { Germinación de la última semilla (días) } \\ \text { Germinación del } 50 \% \text { de las semillas }\end{array} & 39^{\mathrm{c}} & 67^{\mathrm{e}} & 13^{\mathrm{a}} & 6^{\mathrm{b}} & 64^{\mathrm{e}} & 51^{\mathrm{d}} \\ \text { (días) } & 13^{\mathrm{b}} & 24^{\mathrm{c}} & 4^{\mathrm{a}} & 5^{\mathrm{a}} & 40^{\mathrm{e}} & 35^{\mathrm{d}} \\ \text { Porcentaje de germinación total (\%) } & 86^{\mathrm{b}} & 99^{\mathrm{c}} & 97^{\mathrm{bc}} & 93^{\mathrm{bc}} & 86^{\mathrm{b}} & 69^{\mathrm{a}}\end{array}$

${ }^{*}$ Literales diferentes indican diferencias estadísticas significativas

foliáceos, la mayoría son simples aunque en C. tapia son trifoliados y en $H$. campechianum son bifoliados. A. glabra y C. tapia no presentan ningún tipo de estípula, siendo la ócrea característica de C. barbadensis. Los metafilos son simples en $A$. glabra y $C$. barbadensis, pentafoliados en $C$. pentandra y $P$. aquatica, trifoliados en C. tapia y paripinados en $H$. campechianum (Cuadro 3).

\section{Caracterización morfológica de las plán- tulas en estudio:}

\section{Annonaceae}

\section{Annona glabra}

Germinación fanerocotilar epigea, curvada. A los seis días el hipocótilo presenta de 8 a $8.5 \mathrm{~cm}$ de longitud, 2 a $3 \mathrm{~mm}$ de diámetro, es cilíndrico y glabro, de color café. La raíz es axonomorfa, de 7 a $8 \mathrm{~cm}$ de longitud, de color blanco a café, con pocas raíces secundarias que se encuentran presentes hacia la base del cuello.

A los 11 días se presentan los cotiledones, son foliáceos, opuestos, de 1.3 a $2.5 \mathrm{~cm}$ de longitud, 0.9 a $1.1 \mathrm{~cm}$ de ancho, limbo elíptico, base redondeada, margen entero, ápice agudo, pecíolo menor a $0.5 \mathrm{~cm}$, nervación eucamptódroma, de color verde oscuro. El epicótilo es corto, de 1.5 a $2 \mathrm{~cm}$, cilíndrico, color café.
A los 37 días, la plántula alcanza una altura mayor a $18 \mathrm{~cm}$. El sistema presenta finas y abundantes raíces secundarias, de 1 a $3 \mathrm{~mm}$ de diámetro, de color blanco a café. Protofilos alternos simples, de 3.9 a $5 \mathrm{~cm}$ de longitud, 1.4 a $1.7 \mathrm{~cm}$ de ancho, limbo elíptico, base cuneada, margen entero, ápice acuminado, nervación eucamptódroma, de color verde intenso, pecíolo de $0.5 \mathrm{~cm}$. Metafilos alternos simples, de 3.7 a $4.5 \mathrm{~cm}$ de longitud, 1.4 a $2 \mathrm{~cm}$ de ancho, limbo elíptico, base cuneada, margen entero, ápice acuminado, nervación eucamptódroma, de color verde intenso, pecíolo de 0.5 a $0.8 \mathrm{~cm}$ (Fig. 2).

\section{Bombacaceae}

\section{Ceiba pentandra}

Germinación fanerocotilar epigea, curvada. A los tres días, el hipocótilo presenta de 2.5 a $3 \mathrm{~cm}$ de longitud, diámetro de 2 a $3 \mathrm{~mm}$, de color verde amarillento, es cilíndrico y glabro, de mayor grosor hacia la base. La raíz es axonomorfa sin raíces secundarias, de 1.6 a $1.9 \mathrm{~cm}$ de longitud, de color blanco-amarillento. Hasta este momento la testa siguió presente.

A los 5 días presenta cotiledones foliáceos, opuestos, bien desarrollados, de color verde oscuro, pecíolo menor a $0.5 \mathrm{~cm}$. El hipocótilo alcanza de 5 a $5.4 \mathrm{~cm}$ de longitud, 2 a $4 \mathrm{~mm}$ de diámetro, cilíndrico, glabro, coloración rojiza 


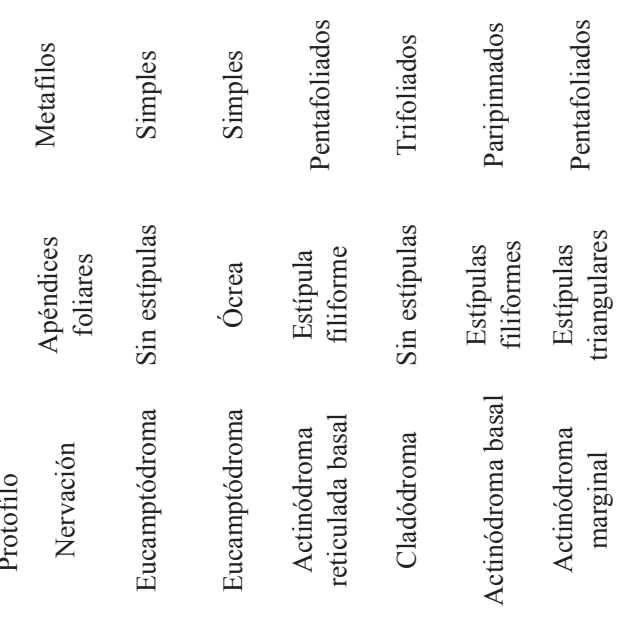

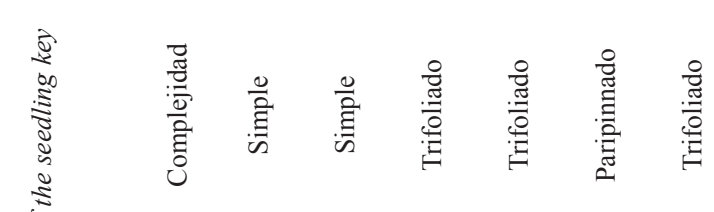

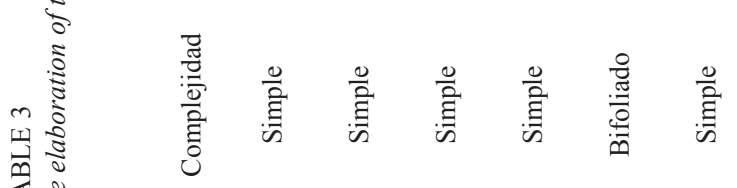

范

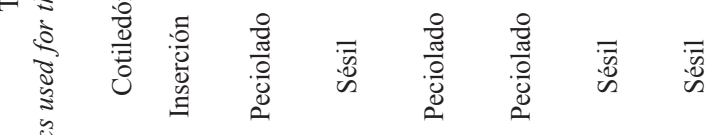

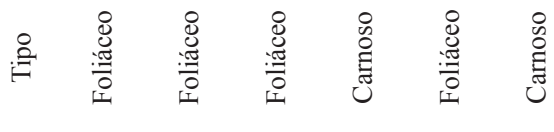

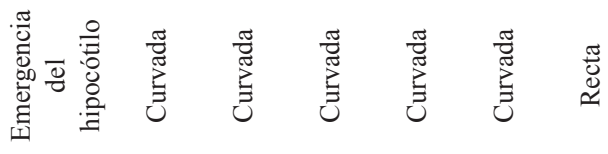

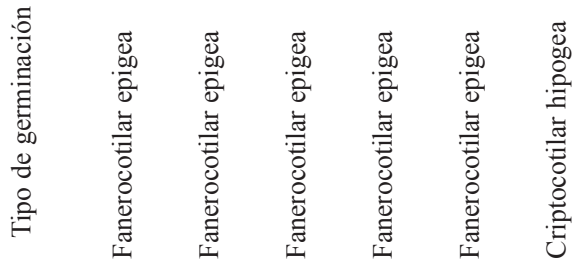

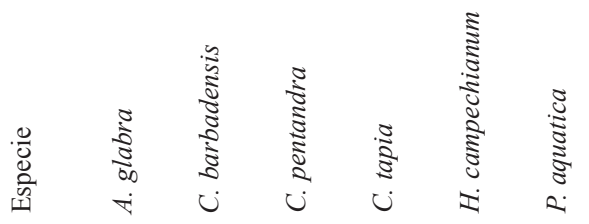




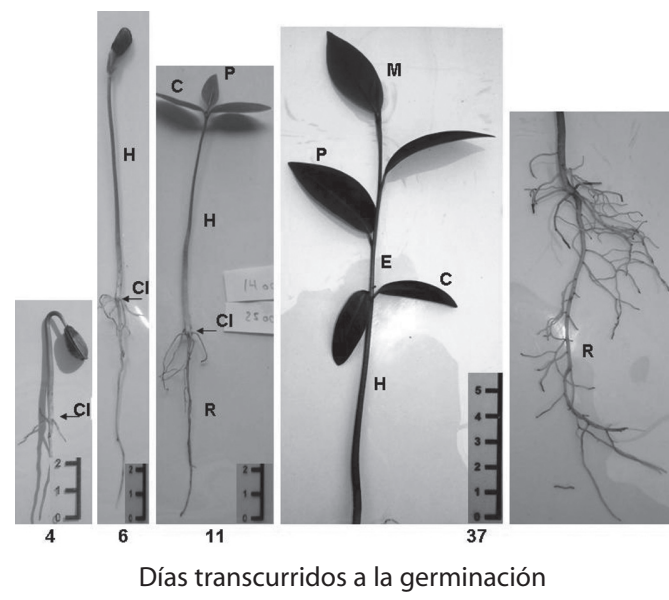

Fig. 2. Estadios tempranos de plántulas de Annona glabra. H: Hipocótilo, C: Cotiledón, E: Epicótilo, P: Protofilos, M: Metafilos, Cl: Cuello, R: Raíz.

Fig. 2. Early stages in seedlings of Annona glabra. H: Hypocotyl, C: Cotyledon, E: Epicotyl, P: Protophylls, M: Metaphylls, Cl: Neck, R: Root.

en los dos tercios inferiores de su longitud y verde claro a amarillento en la parte superior. La raíz alcanza más de $3.5 \mathrm{~cm}$ de longitud, apareciendo pocas raíces secundarias de color blanco a café o negro, cuya longitud varía de 0.5 a $2.5 \mathrm{~cm}$.

A los 16 días, los cotiledones presentan de 3.5 a $4.2 \mathrm{~cm}$ de longitud y 2.8 a $3.2 \mathrm{~cm}$ de ancho, limbo ovado, base redondeada, margen entero, ápice apiculado, nervación actinódroma reticulada y basal, de color verde oscuro, pecíolo de 0.8 a $1.2 \mathrm{~cm}$ de longitud. El hipocótilo se tornó rojizo casi en su totalidad, aumentando su crecimiento en longitud a más de $6 \mathrm{~cm}$ y hasta en $4 \mathrm{~mm}$ de diámetro. Epicótilo de 0.8 a $1.2 \mathrm{~cm}$, de color verde claro y cambiando a rojizo conforme madura. La raíz alcanza $7-8 \mathrm{~cm}$ de longitud, su coloración cambió de blanco amarillento a café, apareciendo mayor número de raíces secundarias y terciarias, las cuales aumentaron su longitud de 3 a $4 \mathrm{~cm}$.

A los 19 días. Los protofilos (3) son alternos en espiral, trifoliados de color verde intenso, el foliolo central de 6.5 a $7 \mathrm{~cm}$ de longitud, 1.8 a $2.2 \mathrm{~cm}$ de ancho, y los laterales de 5.4 a $5.7 \mathrm{~cm}$ de longitud y 1.3 a $1.6 \mathrm{~cm}$ de ancho, limbo lanceolado, base atenuada, margen ligeramente aserrado, ápice acuminado-apiculado, nervación anastomosada; pecíolo de $2.7 \mathrm{~cm}$ de longitud, de coloración rojiza en la mitad inferior y verde claro en la mitad superior, se torna totalmente rojizo conforme pasan los días. El epicótilo de 1.7 a $3 \mathrm{~cm}$ de longitud, presenta una coloración verde claro. Con estípulas alargadas.

A los 37 días, en el nudo cuatro aparecen los metafilos, son digitado-compuestos, pentafoliados, alternos en espiral. El hipocótilo alcanza hasta $8 \mathrm{~cm}$ y el epicótilo de 4 a $5 \mathrm{~cm}$. A los 45 días, los metafilos se han formado completamente. El pecíolo es pulvinado, de 5 a $7 \mathrm{~cm}$ de longitud, coloración verde y rojiza en el extremo donde inician los foliolos; foliolos de 11.5 a $17 \mathrm{~cm}$ de longitud, y 6.5 a $9.8 \mathrm{~cm}$ de ancho. Haz verde oscuro y envés verde claro-pálido. Foliolos angostamente elípticos, base cuneada, margen ligeramente aserrado. La planta alcanza una altura de 33 a $40 \mathrm{~cm}$ y la raíz $15 \mathrm{~cm}$ de longitud o más y $3 \mathrm{~mm}$ de diámetro en la base (Fig. 3).

\section{Pachira aquatica}

Germinación criptocotilar hipogea, recta. A los seis días, el hipocótilo presenta de 1.5 a $2.5 \mathrm{~cm}$ de longitud, diámetro poco menos de $1 \mathrm{~cm}$, de color café, cilíndrico y se encuentra cubierto completamente por los cotiledones o es posible observarlo en una porción lateral. La raíz es axonomorfa con 13 a $15 \mathrm{~cm}$ de longitud, presenta abundantes raíces secundarias hacia la base del cuello, de 2 a $3.5 \mathrm{~cm}$ de longitud, de color blanco-grisáceo a café. Cotiledones carnosos opuestos, anisocótilos, de forma angular, color verde intenso. Epicótilo cónico, de 8.5 a $10 \mathrm{~cm}$ de longitud, 5 a $8 \mathrm{~mm}$ de diámetro, carnoso, ligeramente ensanchado hacia la base, con abundantes lenticelas y estípulas filiformes menores a $5 \mathrm{~mm}$, de color verde intenso. En la base del epicótilo presenta bandas cuticulares exfoliantes de color café.

A los 15 días, el epicótilo se ha elongado de 40 a $50 \mathrm{~cm}$, de 5 a $8 \mathrm{~mm}$ de diámetro, es glabro 


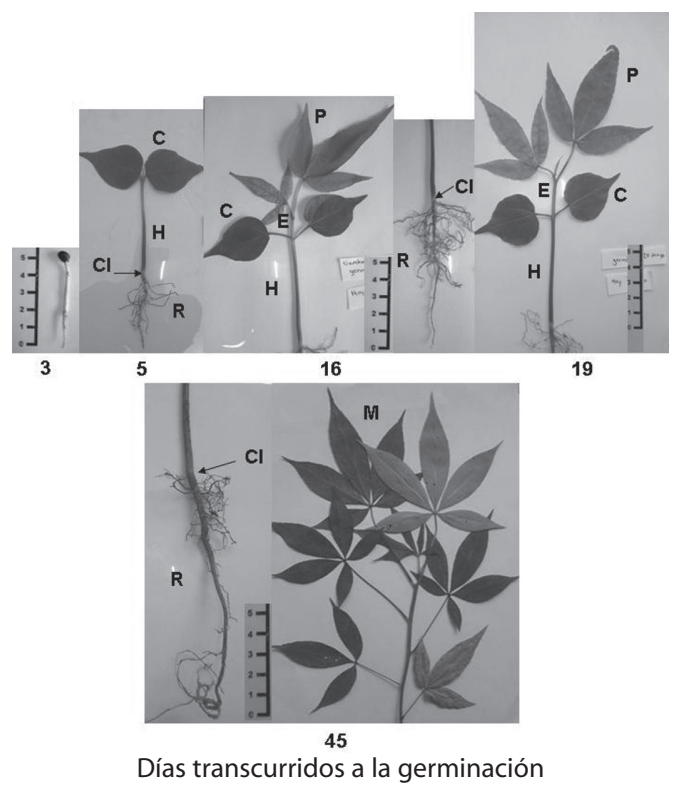

Fig. 3. Estadios tempranos de plántulas de Ceiba pentandra. H: Hipocótilo, C: Cotiledón, E: Epicótilo, P: Protofilos, M: Metafilos, Cl: Cuello, R: Raíz.

Fig. 3. Early stages in seedlings of Ceiba pentandra. H: Hypocotyl, C: Cotyledon, E: Epicotyl, P: Protophylls, M: Metaphylls, Cl: Neck, R: Root.

de forma cónica con ligero ensanchamiento hacia la base, lenticelas y estípulas persistentes filiformes mayores a $4 \mathrm{~mm}$ de longitud, de color verde intenso-brillante y hacia la base presenta un color blanquecino-café. Durante estos días aparece el primer y único protofilo, trifoliado, alterno en espiral, bien desarrollado, de 4.5 a $6 \mathrm{~cm}$ de longitud, 2.4 a $2.7 \mathrm{~cm}$ de ancho, limbo elíptico, base atenuada, margen entero, ápice agudo, nervación actinódroma, de color verde lustroso en el haz y envés verde claro, con pecíolo de 2.4 a $2.7 \mathrm{~cm}$ de longitud.

A los 18 días se presentan los metafilos, son compuestos pentafoliados, alternos en espiral, bien desarrollados, de $11-14 \mathrm{~cm}$ de longitud, 2.4 a $3 \mathrm{~cm}$ de ancho, limbo elíptico lustroso, base atenuada, margen entero, ápice agudo, nervación actinódroma marginal, pecíolo de 4 a $5 \mathrm{~cm}$ de longitud, estípulas de $5 \mathrm{~mm}$ de largo, triangulares. Cuando los metafilos están en proceso de maduración presentan una coloración verde claro para después cambiar a verde oscuro (Fig. 4).

\section{Capparaceae}

\section{Crataeva tapia}

Germinación fanerocotilar epigea, curvada. Al primer día de germinación el hipocótilo presenta de $2-3 \mathrm{~cm}$ de longitud y un diámetro menor a $2 \mathrm{~mm}$. La raíz es axonomorfa, con raíces secundarias muy escasas de color blancoamarillento.

A los tres días los cotiledones son carnosos, opuestos, anisocótilos, ensiformes, persistentes durante 14 días, de color verde intenso, cortamente peciolados de 2 a $3 \mathrm{~mm}$, con presencia de yemas axilares, base atenuada, margen entero,

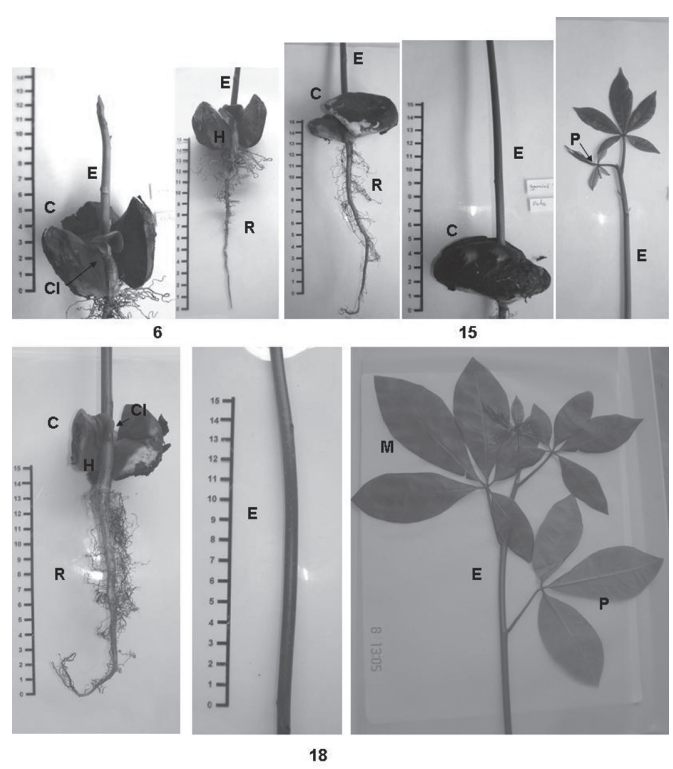

Días transcurridos a la germinación

Fig. 4. Estadios tempranos de plántulas de Pachira aquatica. H: Hipocótilo, C: Cotiledón, E: Epicótilo, P: Protofilos, M: Metafilos, Cl: Cuello, R: Raíz.

Fig. 4. Early stages in seedlings of Pachira aquatica. H: Hypocotyl, C: Cotyledon, E: Epicotyl, P: Protophylls, M: Metaphylls, Cl: Neck, R: Root. 
ápice redondeado, nervación central visible. El cotiledón de mayor tamaño tiene 1.5 a $2.6 \mathrm{~cm}$ de longitud y 4 a $6 \mathrm{~mm}$ de ancho, el cotiledón más pequeño con 1.2 a $1.8 \mathrm{~cm}$ de longitud y 3 a $5 \mathrm{~mm}$ de ancho. Durante este tiempo, se observa la presencia de raíces secundarias de 5 a $7 \mathrm{~mm}$ de longitud de color blanco-amarillento. El hipocótilo es cilíndrico, glabro de 1 a $2.5 \mathrm{~cm}$ de longitud, 2 a $3 \mathrm{~mm}$ de diámetro, color verde claro.

A los 12 días, el hipocótilo alcanza de 4 a $6.3 \mathrm{~cm}$ de longitud y 1 a $2 \mathrm{~mm}$ de diámetro, es cilíndrico, glabro, de color verde intenso, ligeramente ensanchado hacia la base. El epicótilo de 0.8 a $1.7 \mathrm{~cm}$ de longitud, es cilíndrico, de color verde. La raíz alcanza de 3 a $4 \mathrm{~cm}$ de longitud, raíces secundarias de 2 a $3 \mathrm{~cm}$ de longitud, de color blanco a café. El primero y segundo protofilos son opuestos, mientras que el tercer y cuarto protofilos son alternos en espiral, de 3.2 a $3.8 \mathrm{~cm}$ de longitud, 1 a $1.3 \mathrm{~cm}$ de ancho, de color verde claro, pecíolo de 1 a $1.8 \mathrm{~cm}$.

A los 65 días, a partir del cuarto nudo aparecen los metafilos que son similares a los protofilos pero de mayor tamaño, alternos en espiral, trifoliolados, los foliolos de 3.5 a $4.8 \mathrm{~cm}$ de longitud, 1.5 a $2 \mathrm{~cm}$ de ancho, de forma rómbico-lanceolada, base oblicuaatenuada, margen entero, ápice acuminado, nervación cladódroma, sin estípulas, con yemas evidentes, pecíolo de 1.5 a $2 \mathrm{~cm}$. En esta fase, se observan lenticelas de color blanquecino en el eje del tallo (carácter no observable en la figura). El hipocótilo presenta 4.5 a $5.5 \mathrm{~cm}$ de longitud, 2 a $3 \mathrm{~mm}$ de diámetro, es cilíndrico, de color verde. El epicótilo presenta $1 \mathrm{a} 1.5 \mathrm{~cm}$ de longitud, es de color verde intenso. La raíz primaria alcanza $20-22 \mathrm{~cm}$ de longitud, de color blanco-amarillenta, con pocas raíces secundarias (Fig. 5).

\section{Fabaceae}

\section{Haematoxylum campechianum}

Germinación fanerocotilar epigea, curvada. A los tres días, el hipocótilo presenta de 3

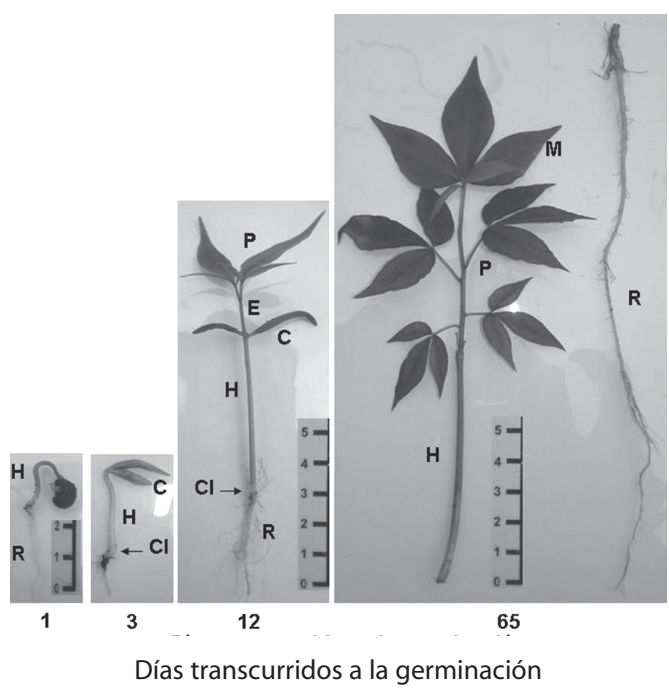

Fig. 5. Estadios tempranos de plántulas de Crataeva tapia. H: Hipocótilo, C: Cotiledón, E: Epicótilo, P: Protofilos, M: Metafilos, Cl: Cuello, R: Raíz.

Fig. 5. Early stages in seedlings of Crataeva tapia. $\mathrm{H}$ : Hypocotyl, C: Cotyledon, E: Epicotyl, P: Protophylls, M: Metaphylls, Cl: Neck, R: Root.

a $3.8 \mathrm{~cm}$ de longitud, 1 a $2 \mathrm{~mm}$ de diámetro, de color verde amarillento a café, es cilíndrico, glabro. La raíz es axonomorfa, de 4 a $4.8 \mathrm{~cm}$ de longitud, muy delgada, color café a negro, con escasos pelos radicales y raíces secundarias. Cotiledones foliáceos, opuestos, sésiles, bifoliados, de 0.6 a $0.8 \mathrm{~cm}$ de longitud y 0.4 a $0.6 \mathrm{~cm}$ de ancho, verde brillante, base atenuado-cuneada, margen entero, ápice oblicuo, nervación actinodroma basal poco visible. El epicótilo es corto, de 2.5 a $3 \mathrm{~cm}$ de longitud, diámetro menor a $2 \mathrm{~mm}$, cilíndrico, glabro, color café claro a rojizo.

A los 10 días, aparecen los protofilos alternos en espiral, paripinnados, con dos pares de foliolos formados completamente, sésiles, de 0.6 a $1.2 \mathrm{~cm}$ de longitud y 0.6 a $0.9 \mathrm{~cm}$ de ancho, color verde brillante en el haz y verde pálido en el envés, limbo cuneiforme, base cuneada o redondeada, margen entero, ápice truncado a profundamente emarginado, con numerosos nervios finos y paralelos, nervación actinódroma, pecíolo de 1.5 a $2 \mathrm{~cm}$ de longitud. 
A los 35 días aparecen los metafilos en el nudo siete, los cuales son paripinnados, alternos en espiral, con tres pares de foliolos sésiles, de 0.6 a $1.2 \mathrm{~cm}$ de longitud y $0.6 \mathrm{a} 1 \mathrm{~cm}$ de ancho, limbo cuneiforme, base cuneada a redondeada, margen entero, ápice truncado a profundamente emarginado, de color verde brillante en haz y verde pálido en el envés, glabros, con numerosos nervios finos y paralelos. Con estípulas filiformes en la base del foliolo, de color rojizo, de 2 a $3 \mathrm{~mm}$. Los metafilos, hasta este momento no alcanzan el tamaño y todos los rasgos de las hojas adultas, pero presentan el número y algunas características de la lámina adulta (Fig. 6).

\section{Polygonaceae}

\section{Coccoloba barbadensis}

Germinación fanerocotilar epigea, curvada. A los 12 días, el hipocótilo presenta de 2.4 a $3.5 \mathrm{~cm}$ de longitud, 1 a $2 \mathrm{~mm}$ de diámetro, es cilíndrico, de color café hacia la mitad y el resto de color amarillento. La raíz es axonomorfa, de 2 a $2.8 \mathrm{~cm}$ de longitud, con pocas raíces secundarias, escasas e incluso ausentes de color café. Cotiledones foliáceos, simples,

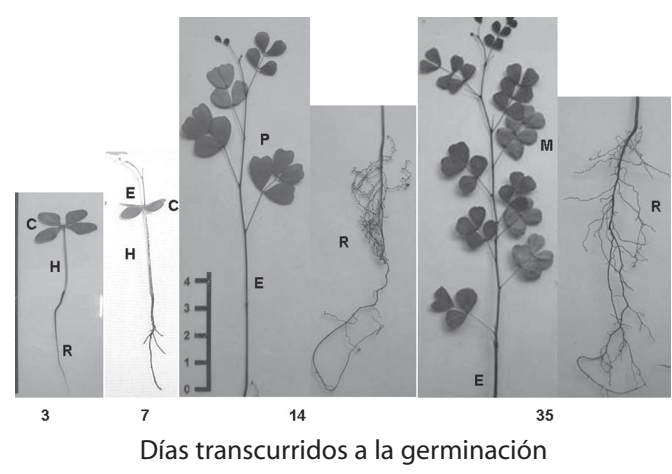

Fig. 6. Estadios tempranos de plántulas de Haematoxylum campechianum. H: Hipocótilo, C: Cotiledón, E: Epicótilo, P: Protofilos, M: Metafilos, Cl: Cuello, R: Raíz.

Fig. 6. Early stages in seedlings of Haematoxylum campechianum. H: Hypocotyl, C: Cotyledon, E: Epicotyl, P: Protophylls, M: Metaphylls, Cl: Neck, R: Root. opuestos, sésiles, de 4 a $7 \mathrm{~mm}$ de longitud, 1 a $1.3 \mathrm{~cm}$ de ancho, pecíolo de 1 a $2 \mathrm{~mm}$, oblato, base redondeada, margen entero, ápice obcordado, nervación visible, color verde oscuro en el haz y verde claro en el envés.

A los 26 días, el hipocótilo se mantiene de color obscuro en más de la mitad inferior del mismo y blanco amarillento en la porción restante, los cotiledones son persistentes. La raíz ha alcanzado de 9.5 a $11 \mathrm{~cm}$ de longitud color café a negro, con abundantes y finas raíces secundarias que presentan de 1 a $2 \mathrm{~cm}$ de longitud. Protofilos simples, alternos en espiral, de 2.4 a $2.8 \mathrm{~cm}$ de longitud, 1.2 a $1.5 \mathrm{~cm}$ de ancho. Durante el proceso de maduración los protofilos aparecen con una tonalidad de color café-claro a café-oscuro, lustrosos. Cuando ha culminado su madurez, cambian a verde claro, presentan limbo elíptico, base cuneada, margen entero, ápice agudo, nervación eucamptódroma. Se presenta pecíolo de 3 a $5 \mathrm{~mm}$ de longitud cuya base rodea a la rama formando una ócrea.

A los 29 días la raíz alcanza de 12 a $15 \mathrm{~cm}$ y presenta en la parte inferior un aumento de raíces secundarias. Hasta este momento el hipocótilo ha cambiado su coloración a caféclaro o café-oscuro. El epicótilo permanece reducido de 0.5 a $1 \mathrm{~cm}$, de color verde oscuro.

A los 148 días los metafilos son simples, alternos, en espiral, de 5 a $6.5 \mathrm{~cm}$ de longitud, 2.8 a $3.5 \mathrm{~cm}$ de ancho, limbo elíptico, base cuneada, margen entero, ápice agudo, nervación eucamptódroma, color verde oscuro, pecíolo de 3 a $15 \mathrm{~mm}$, con ócrea en su base. Raíz axonomorfa de 13 a $15 \mathrm{~cm}$, con gran número de raíces secundarias y con raíces adventicias hacia la base del tallo (Fig. 7).

Se tienen ejemplares de referencia de las fases de desarrollo de las plántulas como producto de esta investigación, depositados en la colección de herbario de El Colegio de la Frontera Sur.

Con base en las características morfológicas se generó la siguiente clave dicotómica para identificar las seis especies de plántulas seleccionadas (Cuadro 3). 
A. Germinación criptocotilar, epicótilo con emergencia recta ............... Pachira aquatica (Fig. 4)

AA. Germinación fanerocotilar, hipocótilo con emergencia curvada

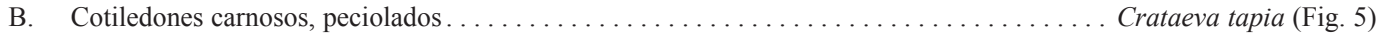

BB. Cotiledones foliáceos

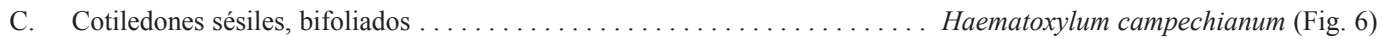

CC. Cotiledones peciolados, enteros

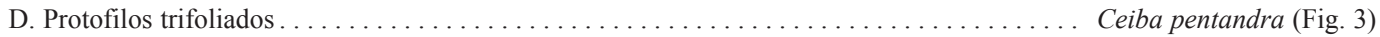

DD. Protofilos simples

E. Con ócrea en la base de hojas, nervación actinódroma . . . . . . . . . . . . . Coccoloba barbadensis (Fig. 7)

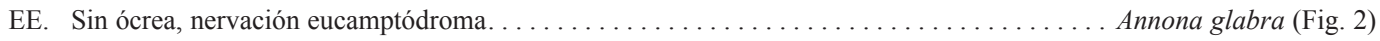

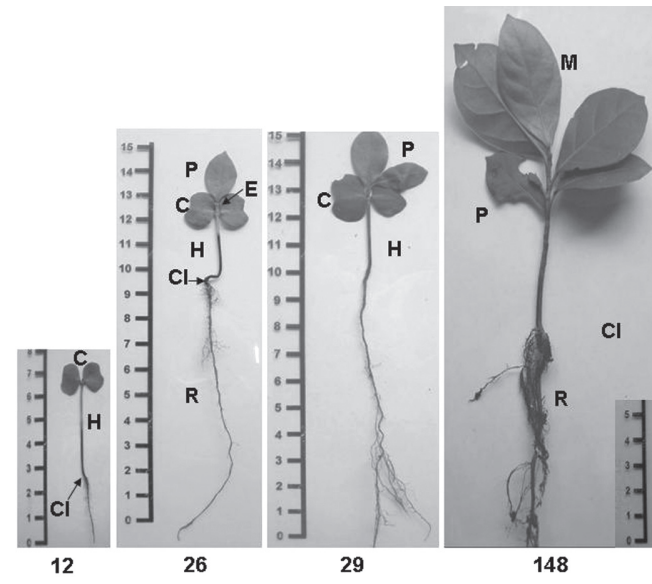

Días transcurridos a la germinación

Fig.7. Estadios tempranos de plántulas de Coccoloba barbadensis. H: Hipocótilo, C: Cotiledón, E: Epicótilo, P: Protofilos, M: Metafilos, Cl: Cuello, R: Raíz.

Fig. 7. Early stages in seedlings of Coccoloba barbadensis. H: Hypocotyl, C: Cotyledon, E: Epicotyl, P: Protophylls, M: Metaphylls, Cl: Neck, R: Root.

\section{DISCUSIÓN}

Germinación: Los días requeridos para el inicio de la geminación sugieren que este proceso es rápido, lo cual pudo deberse a que las semillas fueron sembradas casi de inmediato después de la colecta sin modificar su viabilidad. Sin embargo, es posible que también las diferencias morfológicas de las semillas y la aplicación de tratamientos pregerminativos, causaran las diferencias estadísticas significativas y favorecieran la germinación de A. glabra pero no la de C. barbadensis la cual obtuvo el porcentaje más bajo de germinación al final del experimento; particularmente en esta especie se sospecha la existencia de baja viabilidad del embrión.

Con base en su rápida germinación, las especies bajo estudio corresponden a las recalcitrantes (Schmidt 2000; Mulawarman et al. 2003) por lo que pierden su viabilidad rápidamente. $H$. campechianum y $C$. pentandra requieren mayor humedad en los primeros días de la siembra además de que las características de su testa facilita la permeabilidad al agua, esto se confirma con los pocos días que necesitaron para la germinación de la última semilla. En $P$. aquatica a los seis días se descomponen las semillas debido a su suculencia y el alto contenido de agua.

Salazar et al. (2000) reportaron un 70\% de germinación para $C$. pentandra bajo tratamientos pregerminativos de inmersión en agua hirviendo durante un minuto y dejándola en esa agua durante 24 horas, e indicaron que el proceso germinativo se presenta del día 12 al 15 y concluye a los 30 días; trabajando con semillas sembradas casi en forma inmediata a la colecta, ellos obtuvieron $90 \%$ de germinación lo cual coincide con el $93 \%$ obtenido para esta especie en seis días.

Sánchez \& Hernández (2004) sembraron $P$. aquatica y $C$. pentandra, en un sustrato de tierra+grava y obtuvieron 86 y $80 \%$ de germinación. Sautu et al. (2006) utilizaron un sustrato de tierra-arena y registraron 71 y $44 \%$ de germinación para $C$. pentandra y Pachira quinata, respectivamente. Duran et al. (2000) 
remojaron y sembraron semillas en sustrato de tierra+arena obteniendo $70 \%$ de geminación para $C$. pentandra. Todos estos, son menores a los porcentajes registrados en este trabajo para $C$. pentandra y $P$. aquatica. Las semillas de estas especies requieren condiciones de mucha humedad durante los primeros días de siembragerminación, por lo que es posible que el sustrato utilizado por estos autores, no permitió el mantenimiento de la humedad necesaria para la germinación, dada las características de permeabilidad de la grava, en tanto que el sustrato usado en este trabajo (tierra-cascarilla de cacao-arena) posibilitó el mantenimiento de la humedad constante sin exceso; una condición de baja germinación se presenta con sustratos de alta permeabilidad (Sautu et al. 2006). Lo anterior resalta la importancia del sustrato en términos de mantenimiento de la humedad, factor que se debe tomar en cuenta, sobre todo durante los primeros días de la germinación dado que se trata de especies propias de humedales (Ochoa-Gaona et al. 2009).

No se encontró información sobre la germinación de A. glabra, C. barbadensis, $H$. campechianum y C. tapia, por lo que su comportamiento germinativo se equiparó con el de Annona cherimola, A. spraguei, Coccoloba uvifera, Diphysa robiniodes y Crateva benthamii cuyas características de tamaño y forma de semilla permiten hacer algunas aproximaciones. Sautu et al. (2006) registraron para $A$. spraguei un $14.8 \%$ de germinación en 283 días en un sustrato de arena, mientras que Pedraza (1998) registro para $A$. cherimola un $80 \%$ en 29 días utilizando tierra y arena, estas diferencias posiblemente se deban a la permeabilidad del sustrato. En este trabajo para A. glabra se obtuvo un $86 \%$ de germinación, lo cual puede deberse a la siembra inmediata de las semillas y la eficiencia del sustrato en la conservación de la humedad.

La germinación alcanzada por C. barbadensis fue ligeramente menor a la obtenida por Duran et al. (2000) quienes registraron de 70 a $80 \%$ de germinación para C. uvifera. Para $D$. robinioides se registró $99 \%$ de germinación en un sustrato de arena, requiriendo cinco días para el inicio de la germinación y 30 para la última semilla (Sautu et al. 2006), nuestros resultados muestran porcentajes similares para $H$. campechianum, aunque éste se alcanzo en solo 13 días. Finalmente, Parolin (2001) registró para Crataeva benthamii un $40 \%$ de germinación en ocho días, una diferencia notoria respecto a lo aquí encontrado para C. tapia $(86 \%)$.

Los altos porcentajes de germinación ( $\geq 86 \%$ ) para cinco de las especies estudiadas, muestran que son factibles de ser utilizadas para programas de reforestación, bajo métodos sencillos de manejo. Las semillas de testa suave como las de H. campechianum y C. pentandra permite alcanzar $50 \%$ de germinación en menor número de días y mayor porcentaje de germinación con respecto al resto de las especies. Se ha reportado que una buena germinación con fines de planificación para la producción de plántulas y reforestación debe ser $\geq 50$ (Arriaga et al. 1994, Capó 2001).

Descripción y morfología de plántulas: La descripción morfológica de plántulas que se presenta, proporciona un cúmulo importante de caracteres morfológicos que permiten con base en características de los cotiledones, protofilos, metafilos, cambios en la coloración y presencia de algunas estructuras, separar diferentes fases del desarrollo plantular para su identificación en campo, lo cual resulta de gran importancia. En este sentido De Vogel (1980) y Fenner \& Thompson (2005) indican que algunas estructuras que se desarrollan durante las primeras fases desaparecen al continuar su desarrollo, y al omitir dichos caracteres se generan vacíos en la información que no permiten reconocer y establecer relaciones de parentesco o conexiones filogenéticas. Lo anterior cobra mayor relevancia para especies como C. tapia y $C$. barbadensis, las cuales han sido poco estudiadas (Lundell 1942, Howard 1992).

La descripción de plántulas de especies tropicales, así como la sistematización de datos morfológicos y elaboración de claves, se ha desarrollado pobremente. La mayor parte de la investigación en este tópico se ha enfocado en los bosques templados (Del Amo 1979, Ricardi 
et al. 1987, Zevallos-Pollito \& Flores-Bendezú 2003); para humedales han desarrollado investigaciones Duke (1965, 1969), Barros (1976), Sánchez (1993) y Sánchez \& Hernández (2004). En cuanto a los tipos funcionales de plántulas son de destacar los trabajos de Garwood (1996) e Ibarra-Manríquez et al. (2001). Estos últimos, describen el tipo funcional de plántulas de acuerdo a la germinación de 210 especies de árboles y lianas en México, dentro de las cuales se incluyen dos especies y un género de las abordadas en este estudio.

Para H. campechianum, C. barbadensis, $P$. aquatica solo se han elaborado descripciones parciales o claves dicotómicas para su identificación, sin incluir los cambios que ocurren durante el desarrollo plantular (Duke 1965), por ejemplo, en muchos casos los protofilos pueden proporcionar valiosa información por la retención de caracteres ancestrales de valor filogenético (Ricardi 1996).

A diferencia de lo descrito por Sánchez \& Hernández (2004) quienes indican que la coloración de la plántula de $C$. pentandra se mantiene verde a lo largo del desarrollo, se encontró que el hipocótilo, epicótilo, pecíolo en cotiledones y protofilos cambiaron conforme aumenta la edad de la plántula de un color verde a rojiza, lo cual debe considerarse, ya que el color de las partes y órganos de la planta son característicos y sus cambios dependen principalmente de la edad de la plántula y su contenido de humedad (Zevallos-Pollito \& Flores-Bendezú 2003).

Debido a que las semillas de $P$. aquatica se enterraron parcialmente, los cotiledones permanecieron debajo del suelo, sin embargo, se ha observado en campo que los cotiledones quedan en la superficie del suelo. Dado que los cotiledones son de reserva y de germinación criptocotilar (Duke 1969), esta especie se podría considerar como semihipogea (De Vogel 1980). En cuanto a la formación de las primeras hojas, el primer protofilo de $P$. aquatica se registró como trifoliado coincidiendo con lo descrito por Barros (1976), los metafilos fueron pentafoliados como lo describen Sánchez \& Hernández (2004), diferenciándose de una hoja adulta que presenta 7 a 8 foliolos (Pennington \& Sarukhán 2005). Barros (1976) y Sánchez \& Hernández (2004) describen la fase avanzada de las plántulas de $P$. aquatica y $C$. pentandra sin caracterizar los diferentes estadios. Duke (1965) presenta una clave de identificación de plántulas en la que se incluyen entre otras a $P$. aquatica, $H$. campechianum y $C$. pentandra y un género de Coccoloba. Sin embargo, este estudio carece de descripciones de las plántulas y del tiempo en que suceden los cambios, lo cual remarca la contribución de esta investigación, al describir los cotiledones, protofilos, metafilos y los cambios de coloración que se presentan durante las diferentes fases de desarrollo. De igual manera, Duke (1969) indica algunas características para las familias Polygonaceae, Annonaceae, Fabaceae y Bombacaceae, a las cuales pertenecen las especies bajo estudio.

Todas las especies presentaron raíz axonomorfa. Aunque H. campechianum alcanzó menor diámetro, obtuvo una longitud mayor a las demás y la aparición de un mayor número de protofilos en menor tiempo. La especie que requirió mayor número de días para la aparición de protofilos fue C. barbadensis.

Los resultados sobre el crecimiento final de plántulas en invernadero indican que $C$. pentandra, $H$. campechianum, $P$. aquatica, $C$. tapia alcanzan alturas mayores a $35 \mathrm{~cm}$ en siete meses en tanto que A. glabra y C. barbadensis necesitan nueve meses para alcanzar al menos $30 \mathrm{~cm}$, con lo cual el transplante puede realizarse de manera exitosa, habiendo superado el periodo critico de establecimiento.

Bajo las condiciones experimentales trabajadas y considerando la importancia de incluir especies nativas en planes de restauración de humedales, resulta muy prometedor comprobar que la germinación de estas especies en invernadero es fácil y conveniente debido a los problemas de sobrevivencia que tienen las semillas en campo, por lo que resulta importante continuar con el desarrollo de investigaciones sobre tratamientos pregerminativos y descripción morfológica de las especies arbó- 
reas, arbustivas y herbáceas presentes en estos hábitats altamente amenazados.

\section{AGRADECIMIENTOS}

A Simón Hernández de la Cruz y Alfonso Reyes Díaz por el apoyo en el trabajo de campo. A los productores de la R/a. Tabasquillo, Centla quienes otorgaron permisos de acceso para la colecta de semillas. El desarrollo de esta investigación fue posible gracias al apoyo y financiamiento del Fondo S00022005-2 CONACYT-CONAFOR 14794, bajo el proyecto Evaluación de la germinación y establecimiento inicial de árboles nativos con potencial para la restauración de humedales. El CONACYT otorgó beca para realizar estudios de maestría al primer autor (No. 202970). El Colegio de la Frontera Sur Unidad Villahermosa apoyó con fondos concurrentes e infraestructura.

\section{RESUMEN}

Especies arbóreas de humedales son de importancia económica y para fines de restauración. Nosotros describimos el proceso de germinación y morfología de plántulas de seis especies arbóreas nativas típicas del sureste de México: Annona glabra, Ceiba pentandra, Pachira aquatica, Haematoxylum campechianum, Coccoloba barbadensis y Crataeva tapia. Un total de 300 semillas por especie fueron sembradas en una mezcla de arena, cascarilla de cacao y tierra negra (1: 1: 1), y mantenidas en invernadero a $30 \%$ de sombra artificial, de febrero a noviembre de 2007. Se realizó la caracterización morfológica, y elaboró una clave de plántulas con base en: 1) tipo de germinación 2) eje de la plántula y 3) elementos foliares. P. aquatica presenta germinación criptocotilar hipogea, las otras tienen germinación fanerocotilar epigea. Las tasas de germinación fueron altas (>86\%), a excepción de C. barbadensis (69\%).

Palabras clave: humedales, vegetación ribereña, germinación, morfología de plántulas, árbol nativo.

\section{REFERENCIAS}

Arriaga, V., V. Cervantes \& A. Vargas-Mena. 1994. Manual de reforestación con especies nativas: colecta y preservación de semillas, propagación y manejo de plantas. Instituto Nacional de Ecología, SEDESOL, UNAM, México, D.F.
Barba-Macias, E., J. Rangel-Mendoza \& R. Ramos-Reyes. 2006. Clasificación de los humedales de Tabasco mediante sistemas de información geográfica. Universidad y Ciencia 22: 101-110.

Barros G.J. 1976. Propagación y crecimiento inicial de algunas especies forestales nativas de la zona húmeda tropical. Tesis profesional, Universidad Distrital Francisco José de Caldas, Bogota, Colombia.

Capó Arteaga, M.A. 2001. Establecimiento de plantaciones forestales: los ingredientes del éxito. Universidad Autónoma Agraria Antonio Narro, Saltillo, Coahuila, México.

Dalejones E.B., G.S. Helfman, J.O. Harper \& P.V. Bolstad. 1999. Effects of riparian forest removal on fish assemblages in southern Appalachian streams. Conserv. Biol. 13: 1454-1465.

De Vogel, E.F. 1980. Seedlings of dicotyledons. Structure, development, types. Agricultural Publishing and Documentation (PUDOC), Wageningen, Holanda.

Del Amo, S. 1979. Clave para plántulas y estados juveniles de especies primarias de una selva alta perennifolia en Veracruz, México. Biotica 4: 59-108.

Duke, J.A. 1965. Keys for the identification of seedling of some prominent woody species in eight forest types in Puerto Rico. Ann. Mo. Bot. Gard. 52: 314-350.

Duke, J.A. 1969. On tropical seeds, seedlings, systems and systematics. Ann. Mo. Bot. Gard. 56: 125-161.

Duran, G.R., E.A. Dorantes, P.P. Sima \& M. Méndez G. 2000. Manual de propagación de plantas nativas de la Península de Yucatán. Vol. II. Centro de Investigaciones Científicas de Yucatán, Mérida, Yucatán, México.

Fenner, M. \& K. Thompson. 2005. The ecology of seeds. Cambridge University, Nueva York, EEUU.

Font Quer, P. 1985. Diccionario de Botánica. Labor, Barcelona, España.

García, E. 1988. Modificaciones al sistema de clasificación climática de Köppen para adaptarlo a las condiciones de la República Mexicana. Universidad Nacional Autónoma de México, México D.F., México.

Garwood, N.C. 1996. Functional morphology of tropical tree seedlings, p. 59-129. In M.D. Swaine (ed). The ecology of tropical forest tree seedlings. Man and the biosphere series. Vol. 17. UNESCO, Paris and Parthenon, Paris, Francia. 
Gibbs, J.P. 2000. Wetland loss and biodiversity conservation. Conserv. Biol. 14: 314-317.

Guadarrama-Olivera, M.A. \& G. Ortiz-Gil. 2000. Análisis de la flora de la Reserva de la Biosfera de los Pantanos de Centla, Tabasco, México. Universidad y Ciencia 15: 67-104.

Howard, R.A. 1992. Collected notes on Coccoloba L. (Polygonaceae). Brittonia 44: 356-367.

Ibarra-Manríquez, G., M. Martínez-Ramos \& K. Oyama. 2001. Seedling functional types in a lowland rain forest in Mexico. Am. J. Bot. 88: 1801-1812.

Lot, A. \& A. Novelo. 1988. El Pantano de Tabasco y Campeche: la reserva más importante de plantas acuáticas de Mesoamérica. In Memorias del simposio internacional sobre ecología y conservación del delta de los ríos Usumacinta y Grijalva. INIREB y Gobierno del estado de Tabasco, Tabasco, México.

Lot, A. \& F. Chiang. 1986. Manual de herbario. Administración y manejo de colecciones, técnicas de recolección y preparación de ejemplares botánicos. Consejo Nacional de la Flora de México A.C. México D.F., México.

Lundell, C.L. 1942. Undescribed plants from Mexico and Central America. B. Torrey Bot. Club. 69: 387-399.

Moreno, N.P. 1984. Glosario Botánico Ilustrado. Instituto Nacional de Investigaciones sobre Recursos bióticos, Xalapa, Veracruz, México.

Mulawarman, J.M.R., S.M. Sasongko \& D. Irianto. 2003. Tree Seed Management - Seed Sources, Seed Collection and Seed Handling: A Field Manual for Field Workers and Farmers. International Centre for Research in Agroforestry (ICRAF) and Winrock International, Bogor, Indonesia.

Novelo-Retana, A. 2006. Plantas acuáticas de la Reserva de Biosfera Pantanos de Centla. Espacios Naturales y Desarrollo Sustentable A.C. México D.F., México.

Ochoa-Gaona, S., L.F. Zamora-Cornelio, A. Reyes Díaz, D.S. Ramírez Morales \& S. Hernández de la Cruz. 2009. Manejo, colecta y caracterización de seis especies de árboles nativos con potencial para la restauración de humedales. Fray Bartolomé de Las Casas, Chiapas, México.

Olmsted, I. 1993. Wetlands of Mexico, p. 637-677. In D.F. Whigham, D. Dykyjová \& S. Hejný (eds.) Wetlands of the world: inventory, ecology and management. Kluwer, Dordrech, Holanda.
Parolin, P. 2001. Seed germination and early establishment of 12 tree species from nutrient-rich and nutrientpoor Central Amazonian floodplains. Aquat. Bot. 70: $89-103$

Pedraza, R.A. 1998. Germinación de especies arbóreas colectadas en áreas boscosas de la región de Xalapa, Veracruz. Foresta Veracruzana 1:13-18.

Pennington, T.D. \& J. Sarukhán. 2005. Árboles tropicales de México. Manual para la identificación de las principales especies. Universidad Nacional Autónoma de México, Instituto de Ecología, Fondo de Cultura Económica, México D.F., México.

Ricardi, M. 1996. Morfología de los cotiledones de plántulas de algunas familias o géneros presentes en Venezuela como fuente de caracteres para su determinación. Plántula 1: 1-11.

Ricardi, M., C. Hernández \& F. Torres. 1987. Morfología de plántulas de árboles de los bosques del estado de Mérida. Talleres Gráficos Universitarios, Mérida, Venezuela.

Romero, G.J., M.A. García, J.A. Bautista \& A.P.H. Pérez. 2000. Caracterización de la Reserva de la Biosfera Pantanos de Centla. Universidad y Ciencia 15: 15-20.

Salazar, R., C. Soihet \& J.M. Méndez. 2000. Manejo de semillas de 100 especies forestales de América Central. Turrialba, Costa Rica. CATIE. Proyecto de Semillas Forestales: Danida Forest Seed Centre, Humlebaek, Dinamarca.

Sánchez, P.L. 1993. Descripción y clave botánica para plántulas y juveniles de seis especies en una selva mediana subperennifolia en San Felipe Bacalar. Tesis Profesional, Instituto Tecnológico Agropecuario No. 16. Chetumal, Quintana Roo, México.

Sánchez, S.O. \& C. Hernández. 2004. Estudio morfológico de plántulas de la familia Bombacaceae en Quintana Roo. México. Foresta Veracruzana 6: 1-6.

Sautu, A., J.M. Baskin, C.S. Baskin \& R. Condit. 2006. Studies on the seed biology of 100 native species of trees in a seasonal moist tropical forest, Panama, Central America. Forest Ecol. Manag. 234: 45-263.

Schmidt, L. 2000. Guide to Handling of Tropical and Subtropical Forest Seed. Danida Forest Seed Centre, Humlebaek, Dinamarca.

Scott, D.A. \& M. Carbonell. 1986. Inventario de Humedales de la Región Neotropical. International Waterfowl Research Bureau (IWRB) Slimbridge y UICN, Cambridge, Reino Unido. 
Standley, P.C., J.A. Steyermark \& L.O. Williams. 19471976. Flora of Guatemala. Fieldiana Botany, Chicago Natural History Museum, Chicago, EEUU.

SPSS 15.0. 2006. Command Syntax Reference. SPSS Inc., Chicago, IL, EEUU.

Tabilo-Valdivieso, E. 1997. El beneficio de los humedales en América Central. El potencial de los humedales para el desarrollo. Programa Regional de Manejo de vida silvestre para Mesoamérica y el Caribe. Universidad Nacional y WWF Oficina Regional para Centroamérica, Heredia, Costa Rica.

Zenteno, C.E., L.F. Zamora-Cornelio \& S. Ochoa-Gaona. 2007. Composición y similitud florística de la vegetación riparia de la cuenca baja del Grijalva-Usumacinta, Tabasco, México. In Memorias del XI Congreso
Mesoamericano para la Biología y la Conservación. Oaxtepec, Morelos, México. Revista Mesoamericana 11: 268 .

Zevallos-Pollito, P.A. \& Y. Flores-Bendezú. 2003. Caracterización morfológica de plántulas de "uña de gato" Uncaria tomentosa (Willdernow ex Roemer \& Schultes) D. C. y $U$. guianensis (Aublet) Gmelin del Bosque Nacional Alexander Humboldt. Ecología Aplicada 2: 41-46.

\section{REFERENCIAS DE INTERNET}

Anónimo. 1999. Definición de humedales y sistema de clasificación de tipos de humedales de la Convención de Ramsar (Consultado: 16 diciembre 2008, http:// www.ramsar.org/ris/key ris types s.htm). 